\title{
Cancer Screening Practices among Chinese and Vietnamese in the Greater Houston Area
}

\author{
Beverly Gor ${ }^{1}$, Truong Son Hoang ${ }^{1}$, Jenny $\mathrm{Yi}^{2}$, Angelina Esparza ${ }^{3}$, \\ Mike Hernandez ${ }^{1}$, Lovell A. Jones ${ }^{1}$ \\ ${ }^{1}$ University of Texas M.D. Anderson Cancer Center \\ ${ }^{2}$ University of Houston \\ ${ }^{3}$ American Cancer Society
}

\begin{abstract}
National data on Asian Americans indicate that compared to other groups in the US, cancer incidence and prevalence is relatively lower (Miller, Kolonel et al. 1996; American Cancer Society 2006). However, when the data is examined further based on specific Asian subgroups and for specific cancers, Asian Americans bear a disproportionate burden for cancers of infectious origin, such as cervical, liver, and stomach cancer (Chen 2005). Furthermore, Asian Americans are also experiencing increasing rates of cancers associated with "Westernization," such as breast and prostate cancer (Kolonel, Yoshizawa et al. 1988; Whittemore, Kolonel et al. 1995; Ziegler, Hoover et al. 1996). Early detection and screening are among the frontline strategies in cancer control, yet Asian American and Pacific Islanders have the lowest cancer screening rates of all ethnic groups in the US (American Cancer Society 2006). The Asian American Health Needs Assessment (AsANA) project was designed to collect data on the rapidly growing Asian American community in the Greater Houston area. The AsANA project included a telephone survey to over 800 randomly selected households in the Chinese and Vietnamese communities, two of the largest Asian American subgroups in Texas. Included in the telephone interview were questions regarding cancer screening practices. This article describes the reported screening practices among the surveyed populations and discusses the implications for developing targeted programs that can address cancer screening disparities in this community.
\end{abstract}

(C)2007 Californian Journal of Health Promotion. All rights reserved.

Keywords: cancer screening, disparities, Chinese, Vietnamese

\section{Background}

Asian Americans are the only racial/ethnic population to experience cancer as the leading cause of death. It is the second leading cause of death for other racial and ethnic groups (National Center for Health Statistics 2003; Chen 2005; James, Thomas et al. 2007). Cancer is number one killer for API males and female combined, (all ages, 25-44,45-64), API females, (all ages, 25-44, 45-64) and API males (2544,45-64) (National Center for Health Statistics 2003; California Endowment 2007).

Their cancer burden is described as unusual and unnecessary (Chen, 2005). Unusual in that it includes a disproportionate share of cancers associated with infectious agents, such as cervical (human papilloma virus), stomach (Helicobacter pylori), and liver (hepatitis B) cancer. The Asian cancer burden is also impacted by the fact that this predominantly immigrant population is undergoing "Westernization" of its diet and lifestyle which increases the risk for cancers of the colon, breast and prostate (Kolonel, Yoshizawa et al., 1988; Whittemore, Wu-Williams et al., 1990; Whittemore, Kolonel et al., 1995; Ziegler, Hoover et al., 1996; Harrison, Kagawa-Singer et al., 2005). Furthermore, cancer disparities among Asians have been characterized as unnecessary, since early detection and screening is available for many of these cancers, but a large percentage do not participate in these preventive health practices (Chen, 2005). 
Healthy People 2010 included national goals for cancer screening (Ghosh 2003). These goals are used to monitor Americans' progress towards these and other specific health behaviors based on surveillance data from the Centers for Disease Control and the National Institutes of Health. Unfortunately, for many of these indicators and objectives, Asian and Pacific Islander (API) data is lacking or considered insufficient for analysis, so it is difficult to assess API health status and participation in health and cancer screenings. In addition, available health data on Asian Americans is usually of limited value because it aggregates the data for a population that is extremely diverse and heterogeneous. An example of data aggregation masking true the health profile in the population is breast cancer prevalence in the Asian American community. While national data may indicate that Asian women have breast cancer rates lower than Black and Caucasian women (Ries, Eisner et al., 2004), independent research that examines individual API ethnic groups reported that Hawaiian women have the second highest breast cancer incidence rate among all American women (Look and Braun, 1995; Miller, Kolonel et al., 1996). Furthermore, acculturated Chinese and Japanese women in the U.S. have elevated risks of breast cancer that approaches the rate of Caucasian women (Ziegler, Hoover et al., 1993).

When the Center for Research on Minority Health (CRMH) at The University of Texas M. D. Anderson Cancer Center was created by a Congressional mandate in November 1999, it was charged with the responsibility of conducting an Asian American Health Needs Assessment to begin addressing the lack of health data on the growing Asian population in Texas, especially specific subgroups. Lack of disaggregated health data for Asian Americans remains a major health disparity for this population. In 2004, Yi et al reported that although Texas has the fourth largest population of Asian Americans (AAs) in the United States, they continue to be the most poorly understood minority group in Texas, especially in regards to health status (Yi, et al., 2004).
The first phase of the Asian American Health Needs Assessment (AsANA) project was to develop a culturally and linguistically appropriate survey instrument that was subsequently used to collect baseline health data from individuals from over 400 Chinese and 400 Vietnamese randomly selected households. Among the many topics included on the AsANA survey instrument were questions on cancer screening. The purpose of this paper is to describe the cancer screening practices reported by these populations and compare them to rates reported by other groups in Texas and the US. Implications for culturally tailored interventions and future monitoring are also discussed.

\section{Demographics of the Survey Population}

The demographics of the participants in the AsANA sample are presented in Appendix A. Only self-identified Chinese and Vietnamese age 18 years and older were surveyed. In order to reflect the Census 2000 information for the four counties, the sample was weighted separately for Chinese and Vietnamese, by age, gender and number of adults in the household. The intent of the weighting procedure was to assure that the AsANA population would be representative of the overall population, adding strength to the generalizability of the overall findings. The results indicated that close to $95 \%$ of the respondents were foreign-born. The Vietnamese participants were older than the Chinese with the mean age of 50 and 48 years, respectively. Chinese respondents were more likely to have higher socioeconomic status than Vietnamese respondents, since there were greater percentages of Chinese represented at higher income levels. Also, $62 \%$ of the Chinese reported completing four or more years of college versus $27.5 \%$ for Vietnamese. Overall, $74 \%$ of the AsANA respondents had health insurance, which is slightly higher than the Texas average (73.2\%), but lower than the national average (85.1\%). However, when each group was examined separately, Vietnamese in the AsANA study had the lowest health insurance coverage in the state, surpassed only by Texas Hispanics. Chinese and Vietnamese participants between the ages of 18 and 24 were the group most likely to lack health insurance. 


\section{Cancer Related Questions}

AsANA participants were asked several questions about their cancer screening behaviors and the sources of their cancer information. The survey items were designed to collect information on clinical breast exam, mammography, Pap test, prostate cancer screening, and colorectal cancer screening. Their responses are described in Table 1 . Table 2 compares the rates of cancer screening reported by AsANA respondents with that of other racial and ethnic groups in Texas and the general population of the U.S.

Table 1

Self-reported Cancer Screening Practices and Knowledge by Ethnicity (ASANA)

\begin{tabular}{|l|c|c|c|c|}
\hline \multicolumn{1}{|c|}{ Question/Response } & \multicolumn{2}{|c|}{ Chinese } & \multicolumn{2}{c|}{ Vietnamese } \\
\cline { 2 - 5 } & Freq. & Wtd. $\%$ & Freq. & Wtd. \% \\
\hline Females age 40 and older & & & & \\
\hline Have you ever had a mammogram? & & & & \\
\hline Yes & 141 & 77.2 & 116 & 67.0 \\
\hline No & 35 & 21.7 & 40 & 33.0 \\
\hline Don't Know/Not Sure & & 0.6 & 0 & 0.0 \\
\hline All Females & & & & \\
\hline Have you ever had a Pap smear? & 200 & 79.9 & 153 & 73.1 \\
\hline Yes & 49 & 19.2 & 58 & 23.9 \\
\hline No & 2 & 0.9 & 1 & 0.5 \\
\hline Don't Know/Not Sure & & & & \\
\hline Males age 40 and older & & & & \\
\hline Have you ever had prostate cancer screening? & 27 & 20.6 & 11 & 6.1 \\
\hline Yes...PSA test & 16 & 15.9 & 23 & 14.6 \\
\hline Yes...DRE & 19 & 14.2 & 42 & 22.4 \\
\hline Yes...Both & 52 & 48.4 & 79 & 56.9 \\
\hline No....Neither & 1 & 0.9 & 0 & 0.0 \\
\hline Don't Know/Not Sure & & & & \\
\hline Females and Males age 50 and older & & & & \\
\hline Ever had any of the following?* & 51 & 23.5 & 46 & 15.3 \\
\hline Colonoscopy & 5 & 3.7 & 25 & 8.5 \\
\hline Flexible sigmoidoscopy & 8 & 3.4 & 18 & 5.1 \\
\hline Double contrast barium enema & 38 & 21.9 & 27 & 8.3 \\
\hline Fecal occult blood test & 6 & 3.7 & 14 & 9.3 \\
\hline $\begin{array}{l}\text { Tested but don't know or not sure which test was } \\
\text { performed }\end{array}$ & & & & \\
\hline Never been tested & 24 & 48.4 & 114 & 55.6 \\
\hline $\begin{array}{l}\text { Do you know where to go to get information on cancer } \\
\text { or cancer services? }\end{array}$ & 136 & 30.7 & 253 & 56.9 \\
\hline Yes & 20 & 4.6 & 21 & 4.2 \\
\hline No & & & \\
\hline Don't Know/ Not Sure & & & \\
\hline
\end{tabular}

*Respondents may have had more than one test for colorectal cancer. 
Table 2

AsANA Cancer Screening Rates Compared to Other Groups in Texas and the US Population

\begin{tabular}{|c|c|c|c|c|c|c|c|}
\hline & \multicolumn{2}{|c|}{ AsANA } & \multicolumn{3}{c|}{ Texas } & US \\
\hline \multicolumn{1}{|c|}{ Cancer Screening } & Chinese & Vietnamese & Whites & Blacks & Hispanics & All & \\
\hline $\begin{array}{c}\text { Mammogram } \\
\text { (\% females 40+ y having } \\
\text { screening in last 2 years) }\end{array}$ & 64.2 & 62.4 & 71.3 & 66.8 & 60.4 & 67.7 & 74.6 \\
\hline $\begin{array}{c}\text { Pap test } \\
\text { (\% females 18+ years having } \\
\text { screening in last 3 years) }\end{array}$ & 69.8 & 66.3 & 83.7 & 91.0 & 79.1 & 82.1 & 85.9 \\
\hline $\begin{array}{c}\text { Prostate cancer screening } \\
\text { (\% 40+ years who had PSA or } \\
\text { DRE) }\end{array}$ & 51.2 & 42.1 & 84.5 & 68.5 & 55.3 & 76.5 & 52.1 \\
\hline $\begin{array}{c}\text { Colorectal cancer screening } \\
\text { (\% adults over 50 y who had a } \\
\text { sigmoidoscopy or colonoscopy) }\end{array}$ & 25.2 & 22.1 & 51.2 & 40.4 & 40.6 & 52.9 & 48.3 \\
\hline
\end{tabular}

Source for Texas and US data: Centers for Disease Control and Prevention (CDC). Behavioral Risk Factor Surveillance System Survey Data. Atlanta, Georgia: U.S. Department of Health and Human Services, Centers for Disease Control and Prevention, 2004.

\section{Breast Cancer Screening}

Women 40 years of age and older in the AsANA sample were asked two questions about breast cancer screening: if they ever had a mammogram and if they had had a mammogram in the last two years. A brief description of the procedure was included in the script of the telephone interview to define a mammogram. Approximately $79 \%$ of the Chinese women and $75 \%$ of the Vietnamese women reported that they had had a mammogram (Table 1). Sixtyfour percent of the Chinese and $62 \%$ of the Vietnamese women indicated they had had a mammogram in the last two years (Table 2). These rates were comparable to those of other racial/ethnic groups in Texas, but were lower than the rate for the general population in Texas and the US.

\section{Cervical Cancer Screening}

All female respondents were asked if they had had a Pap test within the last 3 years. A brief description of the procedure was included in the script of the telephone interview to describe a Pap test. Approximately $70 \%$ of the Chinese females and $66 \%$ of the Vietnamese females reported that they had had the test (Table 1). These rates were lower than all other groups in Texas, the overall Texas rate and the overall U.S. rate (Table 2).

\section{Prostate Cancer Screening}

All males 40 years of age and older in the AsANA sample were asked if they had had prostate cancer screening. Responses were recorded for those who had had the prostate specific antigen test, the digital rectal examination or both. About $51 \%$ of the Chinese and about $42 \%$ of the Vietnamese reported that they had at least one of the tests. These rates were lower than for all the comparison groups in Texas, and the Vietnamese screening percentage was approximately half that of the Texas White population.

\section{Colorectal Cancer Screening}

All AsANA participants 50 years and older were asked if they had had some form of colorectal cancer screening, including fecal occult blood test, double contrast barium enema, flexible sigmoidoscopy, or colonoscopy. Descriptions of these procedures were included in the telephone script to clarify the meaning of these medical terms. Only $25 \%$ of the Chinese and $22 \%$ of the Vietnamese respondents reported having had a sigmoidoscopy or colonoscopy. Again, these rates were lower than all other groups to which they were compared in this analysis. 


\section{Knowledge of cancer resources}

Thirty-one percent of the Chinese respondents and over $56 \%$ of the Vietnamese respondents reported that they did not know where to go for information about cancer or cancer services. This lack of knowledge about cancer resources may be a reflection of the limited English proficiency or recent immigration to the US.

\section{Discussion}

With the exception of breast cancer screening, the Chinese and Vietnamese respondents in the AsANA survey had lower cancer screening rates than other racial/ethnic groups in Texas. One of the possible explanations for this finding is that there have been more efforts to increase breast cancer screening among Asian American population in Houston compared to other cancer screening such as colorectal cancer screening. This clearly suggests that culturally appropriate cancer education and screening program may be effective in increasing cancer screening rates among Asian Americans.

The low cervical cancer screening results are striking in that national data for Vietnamese American women show that they have the highest reported incidence of cervical cancer in the US. The cervical cancer incidence rate among this group is more than seven times greater than the rate for Japanese American women and five times greater than that for U.S. White women (Miller, Kolonel et al., 1996).

Prostate cancer screening using prostate specific antigen blood testing and digital rectal examinations is considered controversial. However, these tests are still recommended for most men 40 years and over to detect early changes in prostate tissue that may be associated with cancer. While prostate cancer incidence among Asian American men is comparatively low (American Cancer Society, 2006), some studies show that the disease is increasing, especially with the adoption of Westernized lifestyle and diet (Kolonel, Yoshizawa et al., 1988; Whittemore, Kolonel et al., 1995). Our data reinforced previous findings and indicated that many Asian American men do not participate in prostate cancer screening (Swan,
Breen et al., 2003; American Cancer Society, 2006).

Colorectal cancer is the second highest cancer among Asian American men in the US, yet a high percentage of the Chinese and Vietnamese individuals in the AsANA survey did not have colorectal cancer screening. Barriers to this screening in this population may include the lack of health insurance, lack of awareness of the need for screening, and fear of clinical findings, especially if there is no affordable or accessible treatment.

\section{Conclusions}

The results of the cancer screening and knowledge questions from the AsANA survey indicate that the Chinese and Vietnamese populations in the Greater Houston area may benefit from culturally and linguistically appropriate educational programs to increase awareness of the importance of cervical, prostate, and colorectal cancer screening for early detection of the disease. They may also need assistance with identifying and accessing cancer screening services and follow up treatment, when needed, especially with the Vietnamese population since they have less English proficiency and are more recently immigrated. Programs developed to educate Asian women about breast cancer and facilitate access to breast cancer screening have been successful in increasing mammography screening (Rezai, Nguyen et al., 2003). Demographic information from the AsANA study indicated that Chinese and Vietnamese respondents differed in socioeconomic status and educational level. Efforts to increase cancer screening awareness should consider these differences. Culturally tailored education programs may increase the chances of the targeted populations understanding the importance of early detection and adopting the guidelines for cancer screening. Finally, because the infrastructure and availability of screening and treatment of certain cancers, such as colorectal cancer, are not as accessible and affordable as they are for breast and cervical cancer, new and innovative strategies may be needed to decrease barriers and facilitate access. 


\section{References}

American Cancer Society. (2006). Cancer facts and figures 2006. Atlanta: American Cancer Society, Inc. Aerican Cancer Society. (2006). Cancer prevention and early detection facts and figures 2006. Atlanta: American Cancer Society, Inc.

California Endowment. (2007). Unequal treatment, unequal health. Woodland Hills, CA: Author.

Chen, M. S., Jr. (2005). "Cancer health disparities among Asian Americans: What we do and what we need to do." Cancer 104(12 Suppl.), 2895-2902.

Ghosh, C. (2003). "Healthy People 2010 and Asian Americans/Pacific Islanders: Defining a baseline of information." American Journal of Public Health 93, 2093-2098.

Harrison, G. G., Kagawa-Singer, M. et al. (2005). "Seizing the moment: California's opportunity to prevent nutrition-related health disparities in low-income Asian American population." Cancer, 104(12 Suppl), 2962-2968.

James, C., Thomas, M. et al. (2007). Key facts: Race, ethnicity \& medical care. Menlo Park, CA: The Henry J. Kaiser Family Foundation.

Kolonel, L. N., Yoshizawa, C. N. et al. (1988). Diet and prostatic cancer: a case-control study in Hawaii. American Journal of Epidemiology, 127, 999-1012.

Look, M. A., and Braun, K. L. (1995). A mortality study of the Hawaiian people 1910-1990. Honolulu, HI, The Queen's Health System, 10-11.

Miller, B. A., L. N. Kolonel, et al. (1996). Racial/ethnic patterns of cancer in the United States 19881992. Retrieved November 7, 2005, from http://seer.cancer.gov/publications/ethnicity/index.html

National Center for Health Statistics. (2003). Deaths, percent of total deaths, and death rates for the 15 leading causes of death in selected age groups, by race and sex: United States, 2003. Retrieved May 1, 2007, from http://www.cdc.gov/nchs/data/dvs/lcwk3_2003.pdf

National Center for Health Statistics. (2003). Table 3. Deaths and percentage of total deaths for the 10 leading causes of death, by race: United States, 2003. Hyattsville, MD, Centers for Disease Control. Retrieved May 1, 2007, from http://www.cdc.gov/nchs/data/hestat/leadingdeaths03 tables.pdf

Rezai, K., Nguyen, T.-U. et al. (2003). Increasing organizational capacity for breast and cervical cancer screening for AAPI women. American Journal of Health Studies 18, 211-218.

Ries, L. A. G., Eisner, M. P. et al. (2004). SEER Cancer Statistics Review, 1975-2001. Retrieved July 17, 2005, from http://seer.cancer.gov/csr/1975_2001/

Swan, J., Breen, N. et al. (2003). Progress in cancer screening practices in the United States: Results from the 2000 National Health Interview Survey. Cancer, 97, 1528-1540.

Whittemore, A. S., Kolonel, L. N. et al. (1995). Prostate cancer in relation to diet, physical activity, and body size in blacks, whites, and Asians in the United States and Canada. Journal of National Cancer Institute, 87, 652-661.

Whittemore, A. S., Wu-Williams, A. H. et al. (1990). Diet, physical activity, and colorectal cancer among Chinese in North America and China. Journal National Cancer Institute 82, 915-926.

Yi, J. K., Gor, B. et al. (2004). What we know and don't know about Asian American health in Texas. Texas Medicne, 100, 64-70.

Ziegler, R. G., Hoover, R. N. et al. (1996). Relative weight, weight change, height, and breast cancer risk in Asian-American women. Journal National Cancer Institute 88, 650-660.

Ziegler, R. G., Hoover, R. N. et al. (1993). Migration patterns and breast cancer risk in Asian-American women. Journal National Cancer Institute, 85, 1819-1827.

\section{Acknowledgements}

This project was supported by the National Center for Minority Health and Health Disparities: Project EXPORT (P60MD00503); Purdue Pharma; the Asian American Network for Cancer Awareness, Research \& Training (U01 CA 86322); and Centers for Disease Control (H57CCH624031). 
$\underline{\text { Author Information }}$

Beverly Gor, EdD, RD, LD, CDE*

Associate Program Director for Community Relations

Center for Research on Minority Health

Department of Health Disparities Research

University of Texas M.D. Anderson Cancer Center

1515 Holcombe, Unit 639

Houston, TX 77030

Ph.: 713-563-2750

Fax.: 713-563-2765

E-Mail: bjgor@mdanderson.org

TruongSon Hoang, BS

Research Assistant II

Center for Research on Minority Health

Department of Health Disparities Research

University of Texas M.D. Anderson Cancer Center

1515 Holcombe, Unit 639

Houston, TX 77030

Jenny Yi, PhD, MPH

Associate Professor

Department of Health and Human Performance

University of Houston

3855 Holman St.

Houston, TX 77204

Angelina Esparza, RN, BSN, BA

Director of Survivorship

American Cancer Society

1599 Clifton Road NE

Atlanta, GA 30329

Mike Hernandez, MS, MA

Department of Biostatistics \& Applied Mathematics University of Texas M.D. Anderson Cancer Center 1515 Holcombe, Unit 447

Houston, TX 77030

Lovell A. Jones, $\mathrm{PhD}$

Director, Center for Research on Minority Health

Professor, Department of Health Disparities Research

University of Texas M.D. Anderson Cancer Center

1515 Holcombe, Unit 639

Houston, TX 77030

* corresponding author 


\section{Appendix A}

Demographics of AsANA Study Participants by Ethnicity

\begin{tabular}{|c|c|c|c|c|}
\hline \multirow{2}{*}{ Demographic Characteristics } & \multicolumn{2}{|c|}{ Chinese } & \multicolumn{2}{|c|}{ Vietnamese } \\
\hline & Freq. & Wtd. \% & Freq. & Wtd. \% \\
\hline \multicolumn{5}{|l|}{ Gender } \\
\hline Male & 154 & 47.8 & 197 & 50.6 \\
\hline Female & 251 & 52.2 & 212 & 49.4 \\
\hline \multicolumn{5}{|l|}{ Age } \\
\hline $18-24$ & 19 & 9.7 & 16 & 13.6 \\
\hline $25-34$ & 55 & 21.5 & 41 & 28.6 \\
\hline $35-44$ & 100 & 26.3 & 92 & 22.3 \\
\hline $45-54$ & 104 & 22.0 & 99 & 18.0 \\
\hline $55-64$ & 67 & 10.1 & 77 & 10.0 \\
\hline $65-74$ & 39 & 6.2 & 65 & 5.2 \\
\hline 75 and over & 21 & 4.2 & 19 & 2.3 \\
\hline \multicolumn{5}{|l|}{ Residency status } \\
\hline Born in the US & 14 & $4.9 \%$ & 6 & 4.6 \\
\hline Foreign-born & 385 & 94.1 & 401 & 95.2 \\
\hline Don’t Know/Not Sure/Refused & 6 & 1.0 & 2 & 0.1 \\
\hline \multicolumn{5}{|c|}{ Highest grade or year of school completed } \\
\hline Never attended school & 4 & 0.7 & 7 & 1.0 \\
\hline Grades 1 through 8 & 17 & 3.0 & 59 & 8.8 \\
\hline Grades 9 through 11 & 17 & 3.8 & 60 & 15.6 \\
\hline Grade 12 or GED & 61 & 14.9 & 118 & 25.8 \\
\hline College 1 to 3 years & 54 & 14.8 & 68 & 22.6 \\
\hline College 4 or more years & 252 & 62.7 & 93 & 25.9 \\
\hline Don’t Know/ Not Sure/Refused & 0 & 0.0 & 4 & 0.3 \\
\hline \multicolumn{5}{|c|}{ Annual household income from all sources } \\
\hline Less than 10,000 & 34 & 5.2 & 47 & 6.6 \\
\hline 10 to 15,000 & 23 & 5.3 & 49 & 8.1 \\
\hline 15 to 20,000 & 28 & 5.7 & 37 & 8.1 \\
\hline 20 to 25,000 & 25 & 6.3 & 29 & 10.2 \\
\hline 25 to 35,000 & 29 & 7.3 & 44 & 8.0 \\
\hline 35 to 50,000 & 55 & 15.1 & 55 & 14.1 \\
\hline 50 to 75,000 & 54 & 13.2 & 56 & 19.6 \\
\hline Over 75,000 & 131 & 35.3 & 43 & 11.7 \\
\hline Don’t Know/Not Sure & 11 & 2.8 & 47 & 13.3 \\
\hline Refused & 15 & 3.8 & 2 & 0.2 \\
\hline \multicolumn{5}{|l|}{ Health insurance } \\
\hline Yes & 326 & 79.8 & 301 & 69.4 \\
\hline No & 78 & 19.9 & 106 & 30.0 \\
\hline Refused & 1 & 0.3 & 2 & 0.6 \\
\hline
\end{tabular}

